\title{
FUNDAMENTOS E APLICAÇÕES AMBIENTAIS DOS PROCESSOS FENTON E FOTO-FENTON
}

\author{
Raquel F. Pupo Nogueira*, Alam G. Trovó, Milady Renata A. da Silva e Ricardo D. Villa \\ Departamento de Química Analítica, Instituto de Química de Araraquara, Universidade Estadual Paulista, CP 355, 14801-970 \\ Araraquara - SP, Brasil \\ Mirela C. de Oliveira \\ Centro de Ensino Superior de Tefé, Universidade Estadual do Amazonas, Estrada do Bexiga, 1085, 69470-000 Tefé - AM, Brasil
}

Recebido em 11/11/05; aceito em 25/5/06; publicado na web em 10/1/07

\begin{abstract}
FUNDAMENTS AND ENVIRONMENTAL APPLICATIONS OF FENTON AND PHOTO-FENTON PROCESSES. Wastewater and soil treatment processes based on Fenton's reagent have gained great attention in recent years due to its high oxidation power. This review describes the fundaments of the Fenton and photo-Fenton processes and discusses the main aspects related to the degradation of organic contaminants in water such as the complexation of iron, the use of solar light as the source of irradiation and the most important reactor types used. An overview of the main applications of the process to a variety of industrial wastewater and soil remediations is presented.
\end{abstract}

Keywords: advanced oxidation processes; photo-Fenton; degradation.

\section{INTRODUÇÃO}

O desenvolvimento de novos produtos químicos tem melhorado significativamente a qualidade de vida da população. A importância de seu papel em muitos setores, como agricultura, indústria, transportes e saúde, é inquestionável. No entanto, tem contribuído drasticamente para a contaminação ambiental principalmente devido ao descarte inadequado de substâncias tóxicas como gases, metais pesados, compostos orgânicos entre outros.

A maior conscientização dos riscos iminentes à saúde humana e a necessidade de conservação dos recursos naturais têm motivado esforços para minimizar o problema da contaminação. Alguns exemplos são a imposição de legislações mais restritivas, que visem a redução da quantidade e toxicidade das emissões, reciclagem e reuso de resíduos, adaptação e otimização de processos de produção e a substituição de matérias-primas tóxicas. Também é de suma importância a utilização de métodos de tratamento de efluentes e de recuperação de ambientes já contaminados, que satisfaçam as restrições impostas.

Neste contexto, os Processos Oxidativos Avançados (POA) têm atraído grande interesse tanto da comunidade científica como industrial. São definidos como os processos baseados na formação de radical hidroxila ( $\mathrm{OH})$, altamente oxidante. Devido ao seu alto potencial padrão de redução ${ }^{1}$ (Equação 1), este radical é capaz de oxidar uma ampla variedade de compostos orgânicos a $\mathrm{CO}_{2}, \mathrm{H}_{2} \mathrm{O}$ e íons inorgânicos provenientes de heteroátomos.

$$
\cdot \mathrm{OH}+\mathrm{e}^{-}+\mathrm{H}^{+} \rightarrow \mathrm{H}_{2} \mathrm{O} \quad \mathrm{E}^{\circ}=2,730 \mathrm{~V} \text { (versus } \mathrm{ENH} \text { ) }
$$

O radical hidroxila é geralmente formado em reações que resultam da combinação de oxidantes como ozônio e peróxido de hidrogênio com irradiação ultravioleta (UV) ou visível (Vis) e catalisadores, como íons metálicos ou semicondutores. Dependendo da estrutura do contaminante orgânico, podem ocorrer diferentes reações envolvendo o radical hidroxila, tais como abstração de átomo de hidrogênio, adição eletrofilica a substâncias contendo insaturações e anéis aromáticos, transferência eletrônica e reações radical-radical descritas a seguir ${ }^{2}$ :

\section{Abstração de átomo de hidrogênio}

Os radicais hidroxila formados são capazes de oxidar compostos orgânicos por abstração de hidrogênio, gerando radicais orgâni$\cos$ (Equação 2). Posteriormente ocorre adição de oxigênio molecular formando radicais peróxido (Equação 3), intermediários que iniciam reações térmicas em cadeia levando à degradação até $\mathrm{CO}_{2}$, água e sais inorgânicos. A reação por abstração de hidrogênio ocorre geralmente com hidrocarbonetos alifáticos:

$\mathrm{RH}+{ }^{\circ} \mathrm{OH} \rightarrow \mathrm{R}^{\cdot}+\mathrm{H}_{2} \mathrm{O}$

$\mathrm{R}^{\bullet}+\mathrm{O}_{2} \rightarrow \mathrm{RO}_{2}^{\bullet}$

\section{Adição eletrofílica}

Adição eletrofílica de radical hidroxila a compostos orgânicos que contêm ligações $\pi$ resulta na formação de radicais orgânicos, como mostrado na Equação 4. Ocorre geralmente com hidrocarbonetos insaturados ou aromáticos:

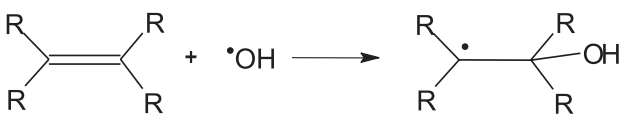

A rápida descloração de clorofenóis também é interpretada pela adição eletrofílica gerando íons cloreto (Equação 5):

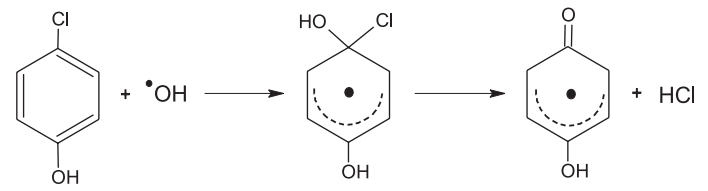

\section{Transferência eletrônica}

Reações de transferência eletrônica ocorrem quando a adição eletrofílica e abstração de hidrogênio são desfavorecidas, como no caso de hidrocarbonetos clorados (Equação 6). 
$\mathrm{RX}+{ }^{\circ} \mathrm{OH} \rightarrow \mathrm{RX}^{\cdot+}+\mathrm{OH}^{-}$

Além destas, outras reações radicalares também podem ocorrer (Equações 7 e 8), no entanto são indesejáveis do ponto de vista de oxidação dos compostos orgânicos, pois consomem radicais ${ }^{\circ} \mathrm{OH}$, prejudicando a eficiência do processo de fotodegradação.

\section{Reações radical-radical}

$\begin{array}{ll}2^{\cdot} \mathrm{OH} \rightarrow \mathrm{H}_{2} \mathrm{O}_{2} & \mathrm{k}_{7}=5,3 \times 10^{9} \mathrm{M}^{-1} \mathrm{~s}^{-1} \\ \mathrm{H}_{2} \mathrm{O}_{2}+{ }^{\circ} \mathrm{OH} \rightarrow \mathrm{HO}_{2}^{\cdot}+\mathrm{H}_{2} \mathrm{O} & \mathrm{k}_{8}=2,7 \times 10^{7} \mathrm{M}^{-1} \mathrm{~s}^{-1}\end{array}$

A predominância de uma ou outra reação dependerá de vários fatores, entre eles a presença e concentração do substrato orgânico, bem como sua recalcitrância.

Os princípios, as características e aplicações dos principais POA foram detalhadamente descritos em uma série de revisões ${ }^{2,3}$. Neste trabalho são discutidos os princípios e principais aplicações dos processos Fenton e foto-Fenton.

\section{O PROCESSO FENTON}

Há mais de um século, a oxidação catalítica de ácido tartárico na presença de sais ferrosos e peróxido de hidrogênio foi relatada por Fenton ${ }^{4}$. Quarenta anos após a primeira observação do que seria a chamada "reação de Fenton" (Equação 9), foi proposto que o radical hidroxila é a espécie oxidante neste sistema, capaz de oxidar várias classes de compostos orgânicos em uma reação espontânea que ocorre no escuro ${ }^{5}$.

$\mathrm{Fe}^{2+}+\mathrm{H}_{2} \mathrm{O}_{2} \rightarrow \mathrm{Fe}^{3+}+{ }^{\circ} \mathrm{OH}+\mathrm{OH}^{-} \quad \mathrm{k}_{9}=76 \mathrm{M}^{-1} \mathrm{~s}^{-1}$

Na ausência de um substrato, o radical hidroxila formado pode oxidar outro íon $\mathrm{Fe}(\mathrm{II})$ como na Equação 10:

$\mathrm{Fe}^{2+}+{ }^{\circ} \mathrm{OH} \rightarrow \mathrm{Fe}^{3+}+\mathrm{OH}^{-} \quad \mathrm{k}_{10}=3,2 \times 10^{8} \mathrm{M}^{-1} \mathrm{~s}^{-1}$

É importante salientar que as espécies de ferro em solução aquosa $\left(\mathrm{Fe}^{2+}, \mathrm{Fe}^{3+}\right)$ existem como aquo-complexos. No entanto, para simplificação do texto foram omitidas as águas de hidratação nas reações representadas.

Os íons férricos formados podem decompor $\mathrm{H}_{2} \mathrm{O}_{2}$ cataliticamente a $\mathrm{H}_{2} \mathrm{O}$ e $\mathrm{O}_{2}$, cujos passos são dependentes do $\mathrm{pH}$ como mostrado nas equações 11-14 e 8, formando também íons ferrosos e radicais. As constantes de velocidade foram determinadas por diferentes autores ${ }^{6}$.

$$
\begin{array}{ll}
\mathrm{Fe}^{3+}+\mathrm{H}_{2} \mathrm{O}_{2} \longrightarrow \mathrm{FeOOH}^{2+}+\mathrm{H}^{+} & \mathrm{k}_{11}=0,001-0,01 \mathrm{M}^{-1} \mathrm{~s}^{-1} \\
\mathrm{FeOOH}^{2+} \rightarrow \mathrm{Fe}^{2+}+\mathrm{HO}_{2}^{\cdot} & \\
\mathrm{Fe}^{2+}+\mathrm{HO}_{2}^{\cdot} \rightarrow \mathrm{Fe}^{3+}+\mathrm{HO}_{2}^{-} & \mathrm{k}_{13}=1,3 \times 10^{6} \mathrm{M}^{-1} \mathrm{~s}^{-1} \\
\mathrm{Fe}^{3+}+\mathrm{HO}_{2} \cdot \mathrm{Fe}^{2+}+\mathrm{O}_{2}+\mathrm{H}^{+} & \mathrm{k}_{14}=1,2 \times 10^{6} \mathrm{M}^{-1} \mathrm{~s}^{-1} \\
\mathrm{H}_{2} \mathrm{O}_{2}+{ }^{\circ} \mathrm{OH} \rightarrow \mathrm{HO}_{2}^{\cdot}+\mathrm{H}_{2} \mathrm{O} & \mathrm{k}_{8}=2,7 \times 10^{7} \mathrm{M}^{-1} \mathrm{~s}^{-1}
\end{array}
$$

Como pode ser visto na Equação $8, \mathrm{H}_{2} \mathrm{O}_{2}$ pode também atuar como seqüestrador de radical hidroxila, formando o radical hidroperoxila $\left(\mathrm{HO}_{2}{ }^{\circ}\right)$, o qual apresenta um menor potencial de redução $\left(\mathrm{E}^{\circ}=1,42 \mathrm{~V}\right.$ versus $\mathrm{ENH}$ ) que ${ }^{\circ} \mathrm{OH}$, prejudicando, portanto, o processo de degradação. Isto ocorre na presença de excesso de $\mathrm{H}_{2} \mathrm{O}_{2}$, pois neste caso, a concentração de $\mathrm{Fe}^{2+}$ no meio é baixa em relação à de $\mathrm{Fe}^{3+}$, uma vez que a reação entre $\mathrm{Fe}^{3+}$ e $\mathrm{H}_{2} \mathrm{O}_{2}$ (Equação 11) é muito mais lenta que a decomposição de $\mathrm{H}_{2} \mathrm{O}_{2}$ na presença de $\mathrm{Fe}^{2+}$ (Equação 9). O efeito prejudicial do excesso de $\mathrm{H}_{2} \mathrm{O}_{2}$ na degradação de compostos orgânicos foi observado na degradação de herbicidas e efluentes, o que demanda uma atenção especial para a utilização da concentração adequada ${ }^{7,8}$.
Somente após quase um século do primeiro trabalho envolvendo a reação de Fenton, esta começou a ser aplicada na oxidação de contaminantes orgânicos presentes em águas, efluentes e solo. Um dos primeiros trabalhos que descreveram a oxidação de compostos orgânicos visando o tratamento de águas por reação de Fenton foi de Barbeni e colaboradores ${ }^{9}$, onde foi estudada a degradação de clorofenóis. A potencialidade do processo para o tratamento de efluentes foi mais tarde enfatizada por Bigda ${ }^{10}$ devido à simplicidade de sua aplicação, uma vez que a reação ocorre à temperatura e pressão ambientes, não requer nenhum reagente ou equipamento especial e se aplica a uma grande variedade de compostos. Além disso, o ferro é o quarto elemento mais abundante na crosta terrestre ${ }^{11}$.

Desde então, um grande número de trabalhos tem demonstrado a aplicabilidade do sistema $\mathrm{H}_{2} \mathrm{O}_{2}$ e sais ferrosos para a degradação de diferentes compostos orgânicos. Apesar de tradicionalmente aceito que o radical hidroxila é a espécie que inicia a oxidação de compostos orgânicos na reação de Fenton, alguns estudos têm sugerido outras espécies oxidantes como intermediários de ferro de alta valência como $\mathrm{FeO}^{3+}(\mathrm{Fe}(\mathrm{V}))$ e o íon ferril, $\mathrm{FeO}^{2+}(\mathrm{Fe}(\mathrm{IV}))^{12}$.

\section{O PROCESSO FOTO-FENTON}

A oxidação de compostos orgânicos sob irradiação UV na presença de íon férrico em meio ácido foi verificada na década de 50, quando foi postulado que a transferência eletrônica iniciada pela irradiação resultava na geração de ${ }^{\circ} \mathrm{OH}$, responsáveis pelas reações de oxidação ${ }^{13}$. A geração de ${ }^{\circ} \mathrm{OH}$ a partir da fotólise de espécies de $\mathrm{Fe}$ (III) foi também observada em processos de oxidação em água atmosférica e em ambientes aquáticos, considerado responsável pela oxidação de hidrocarbonetos em águas superficiais ${ }^{14-16}$. Em solução aquosa, íons férricos existem como aquo-complexos, como por ex. $\left[\mathrm{Fe}\left(\mathrm{H}_{2} \mathrm{O}\right)_{6}\right]^{3+}$ em $\mathrm{pH} 0$, quando na ausência de outros ligantes. Com o aumento do $\mathrm{pH}$, ocorre hidrólise formando espécies hidroxiladas, cuja proporção depende do $\mathrm{pH}$. O primeiro equilíbrio de hidrólise está representado na Equação 15, em que para maior simplicidade foram omitidas as águas de hidratação:

$\mathrm{Fe}^{3+}+\mathrm{H}_{2} \mathrm{O} \rightarrow \mathrm{Fe}(\mathrm{OH})^{2+}+\mathrm{H}^{+}$

Quando complexos de Fe(III) são irradiados, ocorre a promoção de um elétron de um orbital centrado no ligante para um orbital centrado no metal, chamada de transferência de carga ligante-metal ("ligand to metal charge transfer", LMCT), que implica na redução de $\mathrm{Fe}(\mathrm{III})$ a $\mathrm{Fe}(\mathrm{II})$ e oxidação do ligante (Equação 16), formando radical hidroxila ${ }^{17}$ :

$\mathrm{Fe}(\mathrm{OH})^{2+}+h v \rightarrow \mathrm{Fe}^{2+}+{ }^{\circ} \mathrm{OH}$

$\mathrm{O} \mathrm{Fe}^{2+}$ gerado durante irradiação, quando na presença de peróxido de hidrogênio, reage com este dando sequência à reação de Fenton (Equação 9). Neste contexto, a reação é catalítica e é estabelecido um ciclo em que $\mathrm{Fe}^{2+}$ é regenerado. A utilização de $\mathrm{Fe}^{2+/ 3+}$ na presença de peróxido de hidrogênio sob irradiação é chamada de reação foto-Fenton. $\mathrm{O}$ efeito da irradiação na degradação de um contaminante orgânico foi estudado primeiramente por Pignatello ${ }^{18}$, que observou um aumento da velocidade de degradação do herbicida ácido 2,4-diclorofenoxiacético (2,4-D) sob irradiação na presença de peróxido de hidrogênio e $\mathrm{Fe}^{3+}$ em relação à reação na ausência de luz. Este efeito positivo da luz sobre a reação de degradação foi atribuído à redução de $\mathrm{Fe}^{3+}$ a $\mathrm{Fe}^{2+}$ que, por sua vez, reage com $\mathrm{H}_{2} \mathrm{O}_{2}$ dando prosseguimento à reação de Fenton.

A absorbância de íons férricos pode se estender até a região do visível, dependendo do $\mathrm{pH}$, pois o $\mathrm{pH}$ influencia a formação de 
espécies hidroxiladas, as quais apresentam maior absorção no visível. A espécie $\mathrm{Fe}(\mathrm{OH})^{2+}$ apresenta máximo de absorbância em comprimento de onda de $300 \mathrm{~nm}$, estendendo-se até aproximadamente $400 \mathrm{~nm}$, o que permite que a irradiação solar seja utilizada na reação foto-Fenton. Outras informações sobre a especiação de ferro em função de $\mathrm{pH}$ são descritas em outros trabalhos ${ }^{17,19,20}$.

É importante ressaltar que muitas reações fotoquímicas podem ocorrer no sistema foto-Fenton dependendo do espectro de emissão da fonte de irradiação e da absorbância das espécies presentes. A fotólise de $\mathrm{H}_{2} \mathrm{O}_{2}$, que gera dois radicais hidroxila (Equação 17), pode ocorrer simultaneamente ao processo foto-Fenton. No entanto, sua baixa absortividade $\left(18,7 \mathrm{M}^{-1} \mathrm{~cm}^{-1}\right.$ em $\left.254 \mathrm{~nm}\right)$ faz com que tenha um papel pouco importante no processo foto-Fenton, principalmente considerando a absorção de luz pelo ferro e compostos orgânicos.

$\mathrm{H}_{2} \mathrm{O}_{2}+h v \rightarrow 2 \cdot \mathrm{OH}$

Sendo os processos Fenton e foto-Fenton catalisados por íons $\mathrm{Fe}^{2+} / \mathrm{Fe}^{3+}$ e considerando que estes íons são hidrolisados formando hidróxidos insolúveis, o $\mathrm{pH}$ do meio tem um papel muito importante nas reações envolvidas, o que conseqüentemente afeta a velocidade de degradação de compostos orgânicos. A influência do pH na eficiência de degradação de compostos orgânicos foi avaliada em diversos trabalhos sendo observado que uma estreita faixa de $\mathrm{pH}$, entre 2,5 e 3,0, proporciona uma máxima eficiência de degradação ${ }^{18,21}$. Esta faixa limitada é decorrência da precipitação de $\mathrm{Fe}$ (III) em valores de $\mathrm{pH}$ acima de 3 , diminuindo drasticamente sua interação com peróxido de hidrogênio e, conseqüentemente, a produção de ${ }^{\circ} \mathrm{OH}$. Abaixo de $\mathrm{pH} 2,5$, a velocidade de degradação também diminui apesar das espécies de Fe permanecerem solúveis, pois altas concentrações de $\mathrm{H}^{+}$podem seqüestrar radicais hidroxila de acordo com a Equação $18^{22}$ :

$\cdot \mathrm{OH}+\mathrm{H}^{+}+\mathrm{e}^{-} \rightarrow \mathrm{H}_{2} \mathrm{O} \quad \mathrm{k}_{18}=7 \times 10^{9} \mathrm{M}^{-1} \mathrm{~s}^{-1}$

Além disso, a menor absortividade de íons $\mathrm{Fe}\left(\mathrm{H}_{2} \mathrm{O}\right)_{6}{ }^{3+}$ em relação a $\mathrm{Fe}(\mathrm{OH})\left(\mathrm{H}_{2} \mathrm{O}\right)_{5}{ }^{2+}$ e $\mathrm{Fe}(\mathrm{OH})_{2}\left(\mathrm{H}_{2} \mathrm{O}\right)_{4}{ }^{+}$limita a absorção da irradiação ${ }^{19}$. Esta estreita faixa de $\mathrm{pH}$ em que é máxima a eficiência da reação de Fenton e foto-Fenton é uma das grandes limitações do processo, pois há a necessidade de ajuste de $\mathrm{pH}$ para máxima eficiência do tratamento, além da necessidade de neutralização após tratamento antes do descarte em corpos d'água. Para superar a limitação com relação ao $\mathrm{pH}$, algumas estratégias têm sido estudadas como a utilização de complexos de ferro visando sua estabilização até valores de $\mathrm{pH}$ próximos da neutralidade ${ }^{23,24}$, bem como a imobilização de $\mathrm{Fe}$ em membranas ${ }^{25}$. A utilização do processo Fenton ou foto-Fenton heterogêneo com o ferro imobilizado em membranas ou outros suportes apresenta vantagens, como a reutilização do ferro, dispensando procedimentos de remoção de ferro que se fazem necessários considerando os limites de $15 \mathrm{mg} \mathrm{L}^{-1}$ deste metal impostos para o descarte de efluentes tratados.

\section{UTILIZAÇÃO DE COMPLEXOS DE FERRO EM REAÇÕES DE FENTON E FOTO-FENTON}

A utilização de complexos orgânicos de ferro na degradação de contaminantes em reações foto-Fenton tem sido destacada como vantajosa por alguns autores, considerando a estabilização do ferro em uma faixa mais ampla de $\mathrm{pH}$ em relação àquela na ausência de complexos. Por outro lado, o aumento da carga orgânica resultante da adição de ligantes orgânicos tem sido considerada desvantajosa por outros autores. No entanto, tem sido demonstrado que o aumento da carga orgânica no sistema não é uma desvantagem, pois estu- dos demonstram que, em geral, estes são totalmente mineralizados durante o processo ${ }^{26,27}$. Além de permitirem a utilização das reações de Fenton em uma faixa mais ampla de pH, os complexos de ferro também contribuem para o aumento da eficiência de absorção da luz, pois estendem a banda de absorção para a região do visível $^{15}$. O ferrioxalato de potássio (FeOx) é um complexo de $\mathrm{Fe}(\mathrm{III})$ bastante estudado tanto em aplicações fotoquímicas como em processos foto-Fenton. Sua fotólise é bastante sensível à irradiação em comprimentos de onda entre 200 e $500 \mathrm{~nm}$, gerando $\mathrm{Fe}^{2+}$ e $\mathrm{CO}_{2}$ em meio ácido (Equações 19-21) com um rendimento quântico ( $\Phi)$ conhecido, o que possibilita sua utilização como actinômetro químico para medidas da intensidade da irradiação absorvida em um sistema. O rendimento quântico é uma medida da eficiência fotônica de uma reação fotoquímica e é definido como o número de mols de um produto formado, ou reagente consumido, por número de mols de fótons absorvidos ${ }^{28}$ :

$\left[\mathrm{Fe}\left(\mathrm{C}_{2} \mathrm{O}_{4}\right)_{3}\right]^{3-}+h v \rightarrow\left[\mathrm{Fe}\left(\mathrm{C}_{2} \mathrm{O}_{4}\right)_{2}\right]^{2-}+\mathrm{C}_{2} \mathrm{O}_{4}^{-*}$

$\mathrm{C}_{2} \mathrm{O}_{4}^{--}+\left[\mathrm{Fe}\left(\mathrm{C}_{2} \mathrm{O}_{4}\right)_{3}\right]^{3--} \rightarrow\left[\mathrm{Fe}\left(\mathrm{C}_{2} \mathrm{O}_{4}\right)_{2}\right]^{2-}+\mathrm{C}_{2} \mathrm{O}_{4}^{2-}+2 \mathrm{CO}_{2}$

$\mathrm{C}_{2} \mathrm{O}_{4}^{-\cdot}+\mathrm{O}_{2} \rightarrow \mathrm{O}_{2}^{-\bullet}+2 \mathrm{CO}_{2}$

Como mencionado anteriormente, a irradiação de soluções contendo hidroxo complexos de ferro leva à redução de $\mathrm{Fe}^{3+}$ a $\mathrm{Fe}^{2+}$ (Equação 16). No entanto, esta é pouco favorecida, com rendimento quântico relativamente baixo, em torno de $0,14 \mathrm{em} 313 \mathrm{~nm}^{14}$. Na presença de ferrioxalato, o rendimento quântico de geração de $\mathrm{Fe}^{2+}$ aumenta consideravelmente atingindo $1,24 \mathrm{em} 300 \mathrm{~nm}$. O Fe ${ }^{2+}$ fotogerado é consumido na reação de Fenton (Equação 9), tornando o processo cíclico, razão pela qual foi proposto para utilização em processos foto-Fenton, cujos resultados são bastante superiores aos obtidos com sais de ferro, especialmente sob irradiação solar ${ }^{19,29}$.

A presença de ferrioxalato no meio também suprime a absorção de irradiação UV-Vis por intermediários formados durante a degradação de alguns compostos aromáticos. $\mathrm{Na}$ ausência de ferrioxalato estes intermediários diminuem a foto-redução do $\mathrm{Fe}^{3+}$ a $\mathrm{Fe}^{2+}$ e a fotólise do peróxido de hidrogênio. A fotólise do ferrioxalato também gera $\mathrm{Fe}(\mathrm{II})$-oxalatos que reagem rapidamente com $\mathrm{H}_{2} \mathrm{O}_{2}$ gerando radicais hidroxila (Equação 22$)^{30}$.

$\mathrm{Fe}(\mathrm{II})-\mathrm{C}_{2} \mathrm{O}_{4}+\mathrm{H}_{2} \mathrm{O}_{2}+h v \rightarrow \mathrm{Fe}(\mathrm{III})\left(\mathrm{C}_{2} \mathrm{O}_{4}\right)^{+}+{ }^{\cdot} \mathrm{OH}+\mathrm{OH}^{-}$

Hislop e Bolton ${ }^{31}$ sugerem que a eficiência de ferrioxalato em processos foto-Fenton não se deve unicamente à alta absorção de radiação. Quando o radical hidroxila ataca o composto alvo, há a formação de outros radicais (Equação 23), que na ausência de ferrioxalato reagem com o oxigênio, formando o radical hidroperoxila (Equação 24), menos oxidante que o radical hidroxila. Na presença de ferrioxalato há geração continua de $\mathrm{Fe}^{2+}$ (Equação 25) que reage rapidamente com o peróxido de hidrogênio (reação de Fenton, Equação 9) e impede a formação de outros radicais menos oxidantes.

$$
\begin{aligned}
& \cdot \mathrm{OH}+\mathrm{HROH} \rightarrow{ }^{\cdot} \mathrm{ROH}+\mathrm{H}_{2} \mathrm{O} \\
& \cdot \mathrm{ROH}+\mathrm{O}_{2} \rightarrow \mathrm{RO}+\mathrm{HO}_{2}^{\cdot} \\
& \cdot \mathrm{ROH}+\left[\mathrm{Fe}\left(\mathrm{C}_{2} \mathrm{O}_{4}\right)_{3}\right]^{3-} \rightarrow \mathrm{RO}+\mathrm{Fe}^{2+}+2 \mathrm{C}_{2} \mathrm{O}_{4}^{2-}+\mathrm{HC}_{2} \mathrm{O}_{4}^{-}
\end{aligned}
$$

Analisando-se as Equações 23, 25 e 9 observa-se que após a fotólise inicial do ferrioxalato, $\mathrm{Fe}^{2+}$ pode ser gerado na ausência de irradiação, possibilitando um sistema cíclico de geração de $\mathrm{Fe}^{3+} \rightarrow$ $\mathrm{Fe}^{2+}$ no escuro. Entretanto, este ciclo só é possível quando o radical orgânico formado $\left({ }^{\circ} \mathrm{ROH}\right)$ é facilmente oxidado, como os gerados durante a oxidação do 2-propanol e metanol ${ }^{31}$. Caso contrário, o radical pode dimerizar (Equação 26) ou competir com o $\mathrm{H}_{2} \mathrm{O}_{2}$ por $\mathrm{Fe}^{2+}$ (Equação 27) convertendo-se novamente no composto original. 
$\cdot \mathrm{R}+{ }^{\circ} \mathrm{R} \rightarrow \mathrm{R}-\mathrm{R}$

$\cdot \mathrm{R}+\mathrm{Fe}^{2+}+\mathrm{H}^{+} \rightarrow \mathrm{Fe}^{3+}+\mathrm{RH}$

$\mathrm{O}$ uso de ferrioxalato como fonte de ferro em processo fotoFenton tem se mostrado até 30 vezes mais eficiente que os processos $\mathrm{UV} / \mathrm{H}_{2} \mathrm{O}_{2}$ e UV-Vis $/ \mathrm{Fe}^{2+} / \mathrm{H}_{2} \mathrm{O}_{2}$ na oxidação de BTX (mistura de benzeno, tolueno, xileno), 1,4 dioxano e metil-terc-butil-éter. A utilização de $\mathrm{FeOx} / \mathrm{H}_{2} \mathrm{O}_{2}$ /solar na degradação de tricloroetileno é 120 e 50 vezes mais eficiente que os processos $\mathrm{TiO}_{2} / \mathrm{H}_{2} \mathrm{O}_{2} /$ solar e $\mathrm{Fe}^{3+} / \mathrm{H}_{2} \mathrm{O}_{2} /$ solar, respectivamente ${ }^{19,29}$. Alguns compostos resistentes ao tratamento biológico, como EDTA e corantes como vermelho reativo 235 , também podem ser degradados pelo sistema $\mathrm{FeOx} / \mathrm{H}_{2} \mathrm{O}_{2} / \operatorname{solar}^{23,32}$.

Nogueira e colaboradores ${ }^{27}$ avaliaram a degradação de formol, corante verde de malaquita, 4-clorofenol e dos herbicidas tebuthiuron e diuron utilizando os sistemas $\mathrm{Fe}^{3+} / \mathrm{H}_{2} \mathrm{O}_{2} /$ solar e $\mathrm{FeOx} / \mathrm{H}_{2} \mathrm{O}_{2}$ /solar. Nas mesmas concentrações de reagentes e doses de energia solar, a degradação foi significativamente maior na presença de ferrioxalato em relação a nitrato férrico, exceto para o composto 4-clorofenol. A degradação de clorofenóis envolve um mecanismo específico com a formação de intermediários que catalisam a reação de Fenton ${ }^{33}$. A presença de ferrioxalato provavelmente interfere na formação desses intermediários e diminui a velocidade de reação. Apesar de mais lenta, a total degradação de fenol e clorofenóis utilizando ferrioxalato foi observada anteriormente ${ }^{34,35}$.

A presença de altas concentrações de seqüestradores de radicais hidroxila, como alguns álcoois e íons carbonato, pode diminuir a eficiência da reação de Fenton. Na presença de altas concentrações de sulfato, fosfato e terc-butanol, a degradação de 2,4-D é mais rápida quando se utiliza o sistema $\mathrm{FeOx} / \mathrm{H}_{2} \mathrm{O}_{2} / \mathrm{UV}$ que quando se utiliza $\mathrm{Fe}^{3+} / \mathrm{H}_{2} \mathrm{O}_{2} / \mathrm{UV}^{26}$.

$\mathrm{O}$ radical $\mathrm{CO}_{2}^{--}$gerado na fotólise de ferrioxalato (Equações 19 e 28) é capaz de iniciar o processo de redução de percloroalcanos de difícil degradação (Equação 29). Essas espécies reduzidas podem, então, ser totalmente mineralizadas pela reação foto-Fenton (Equações $30-32)^{36}$.

$$
\begin{aligned}
& \mathrm{C}_{2} \mathrm{O}_{4}^{--} \rightarrow \mathrm{CO}_{2}+\mathrm{CO}_{2}^{--} \\
& \mathrm{CO}_{2}^{-}+\mathrm{CCl}_{4} \rightarrow \mathrm{CO}_{2}+\mathrm{CCl}_{3}^{-}+\mathrm{Cl}^{-} \\
& \mathrm{CCl}_{3} \cdot+\mathrm{O}_{2} \rightarrow \mathrm{CCl}_{3} \mathrm{OO}^{-} \\
& \mathrm{CCl}_{3} \mathrm{OO}+\mathrm{Fe}(\mathrm{II})+\mathrm{H}^{+} \rightarrow \mathrm{CCl}_{3} \mathrm{OOH}+\mathrm{Fe}(\mathrm{III}) \\
& \mathrm{CCl}_{3} \mathrm{OOH}+\mathrm{H}_{2} \mathrm{O} \rightarrow 3 \mathrm{H}^{+}+3 \mathrm{Cl}^{-}+\mathrm{CO}_{2}+1 / 2 \mathrm{O}_{2}
\end{aligned}
$$

Alguns estudos relatam a formação de complexos de ferro durante o processo de degradação, produtos de reações entre o ferro e o composto alvo e/ou seus intermediários ${ }^{14,37-39}$. Como exemplo pode ser citada a degradação do corante laranja ácido 7 (AO7) na ausência de $\mathrm{H}_{2} \mathrm{O}_{2}$, onde são formados complexos com $\mathrm{Fe}$ (III), que sob irradiação visível são fotolisados, gerando $\mathrm{Fe}^{2+}$ e um radical $\mathrm{AO}^{{ }^{++}}$o qual inicia a degradação do corante ${ }^{39}$. Sun e Pignatelo ${ }^{40}$ também atribuíram o segundo estágio da degradação de 2,4-D à fotólise de complexos de ferro formados com produtos da degradação deste pesticida. Estes intermediários geralmente são moléculas polidentadas contendo grupos carboxila e hidroxila (Equações 33 e 34).

$$
\begin{aligned}
& {\left[\mathrm{RCO}_{2}-\mathrm{Fe}\right]^{2+}+h v \rightarrow\left[\mathrm{R}^{\cdot}\right]+\mathrm{CO}_{2}+\mathrm{Fe}^{2+}} \\
& {[\mathrm{ROH}-\mathrm{Fe}]^{3+}+h v \rightarrow[\mathrm{RO}]^{\cdot}+\mathrm{Fe}^{2+}+\mathrm{H}^{+}}
\end{aligned}
$$

A adição de certos ligantes durante uma determinada etapa da reação de degradação também tem sido estudada com o objetivo de acelerar o processo. Um exemplo é a adição do ácido cianúrico, que diminui de 24 para $8 \mathrm{~h}$ o tempo de degradação do corante laranja II. Este aumento na velocidade de degradação deve-se à for- mação de um complexo entre o ácido cianúrico e $\mathrm{Fe}^{3+}$ que catalisa a decomposição de $\mathrm{H}_{2} \mathrm{O}_{2}$ na reação de Fenton $^{38}$.

Zeep e colaboradores ${ }^{16}$ apontaram a possibilidade de utilização de citrato de ferro(III) em reações foto-Fenton para tratamento de efluentes. Apesar da formação de $\mathrm{Fe}^{2+}$ por este complexo ter rendimento quântico um pouco menor que por ferrioxalato, sua vantagem está no fato de ser menos tóxico, poder ser usado em altos valores de $\mathrm{pH}$ (até $\mathrm{pH}=9$ ) e por ser o ácido cítrico bastante disponível (é encontrado em altas concentrações em suco de limão, por ex.). Quando Sun e Pignatello ${ }^{24}$ utilizaram este quelato em pH 6 sem incidência de luz este foi inativo na degradação de 2,4-D. No entanto, sob irradiação, $100 \%$ de degradação de 2,4-D foi atingida em aproximadamente $7 \mathrm{~min}^{40}$.

\section{PROCESSO FOTO-FENTON ATIVADO POR IRRADIAÇÃO SOLAR}

A eficiência de degradação de diferentes classes de compostos orgânicos tóxicos tem tornado o processo foto-Fenton ativado por luz solar bastante atrativo ${ }^{29,32,41-44}$. Os estudos vão desde a utilização de diferentes complexos de ferro ${ }^{23,29}$, até a construção de reatores que permitem um melhor aproveitamento da irradiação solar incidente ${ }^{42,45-47}$.

Trabalhos realizados na Plataforma Solar de Almeria (PSA) na Espanha demonstram o uso de reatores parabólicos concentradores de energia na degradação de diversos contaminantes orgânicos. Estes reatores também são conhecidos como PTC ("Parabolic-Trough Collectors"), cujo esquema é apresentado na Figura 1.

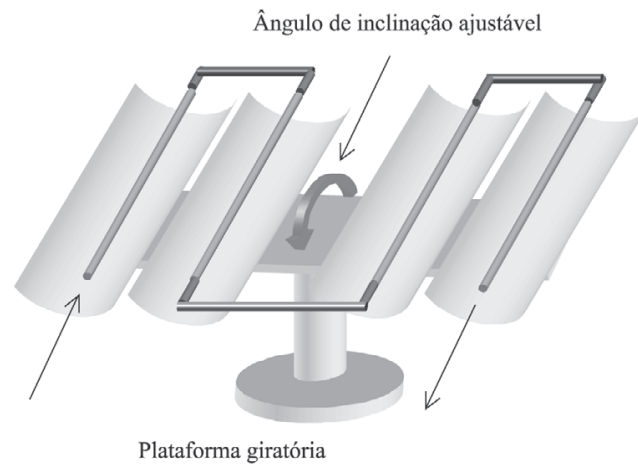

Figura 1. Representação esquemática do reator parabólico concentrador de energia solar (PTC)

O PTC é constituído de parábolas refletoras que convergem a irradiação incidente a tubos de polietileno transparente fixados paralelamente à mesma. $\mathrm{O}$ ângulo de inclinação do conjunto de parábolas pode ser ajustado automaticamente, de modo a obter o máximo aproveitamento da radiação solar. Este sistema tem um motor que permite que os coletores acompanhem a radiação, para que o plano do coletor seja sempre perpendicular aos raios solares. As primeiras aplicações deste tipo de reator à fotodegradação de contaminantes orgânicos em água utilizaram a fotocatálise heterogênea com $\mathrm{TiO}_{2}$ em suspensão ${ }^{45}$.

Nitrobenzeno, aminosilicone e fenol são alguns dos exemplos de compostos eficientemente degradados utilizando PTC ${ }^{42,48}$. Will

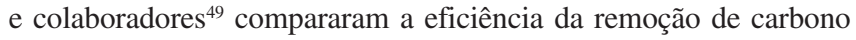
orgânico total (COT) de uma solução com diferentes concentrações de fenol (100 e 1000 ppm de COT) em um reator anular com irradiação artificial e em um PTC. Esses autores observaram que para a menor concentração do contaminante, a eficiência de remoção de COT é igual em ambos os reatores. No entanto, na presença de 1000 ppm de COT, o reator com irradiação artificial proporcionou 
melhores resultados, como conseqüência da maior dose de energia aplicada em comparação ao PTC. Apesar de alguns estudos demonstrarem a aplicação deste tipo de reator solar para a degradação de diversos compostos, o reator PTC foi originalmente projetado para aplicações térmicas e apresenta desvantagens como o aproveitamento somente da radiação direta, perdendo a radiação difusa que não pode ser concentrada em um ponto (eixo focal dos coletores parabólicos), além de seu alto custo e problemas de superaquecimento da amostra ${ }^{50}$.

Um outro tipo de reator é o de fluxo laminar, o qual não concentra irradiação solar e sim baseia-se na irradiação de uma lâmina de solução, contendo o composto-alvo, que passa em fluxo sobre uma placa de vidro com um ângulo de inclinação geralmente fixo, que depende da latitude local ${ }^{51}$. Moraes e colaboradores ${ }^{47}$ conseguiram $^{2}$ reduzir aproximadamente 90 e $66 \%$ da concentração de COT de uma solução aquosa de gasolina e efluente de uma refinaria de petróleo, respectivamente. Outros compostos como, vanilina, ácido gálico, ácido cumárico e L-tirosina, têm sido eficientemente mineralizados utilizando reatores de fluxo laminar ${ }^{51}$. Este reator tem vantagens frente ao PTC, como a simplicidade e o baixo custo para aplicação e manutenção. No entanto, necessita de uma grande área de exposição, o que pode restringir seu uso.

A combinação do PTC ao reator de fluxo laminar resultou no reator coletor parabólico composto (CPC). Os CPCs são provavelmente os reatores solares mais utilizados, pois apresentam a melhor relação óptica para aproveitamento da energia solar. São reatores estáticos com uma superfície refletora complexa ao redor do cilindro reator. Nesta concepção, praticamente toda radiação é aproveitada (direta e difusa). A radiação refletida é distribuída na parte inferior do tubo o que faz com que toda a circunferência seja iluminada (Figura 2).

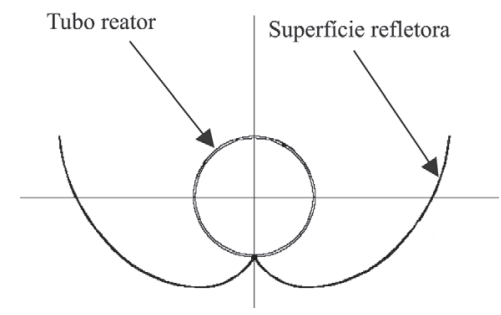

Figura 2. Perfil de reflexão do coletor parabólico composto (CPC)

O fato de este reator apresentar a simplicidade do reator de fluxo laminar porém com maior aproveitamento da radiação tem contribuído para sua maior utilização na degradação de pesticidas, surfactantes, efluentes industriais, entre outros $\operatorname{compostos}^{41,44,52,53}$. Machado e colaboradores ${ }^{54}$ avaliaram o uso do CPC na degradação de efluentes de uma indústria de processamento de batatas. Foi estimado que um reator com uma superfície coletora de $370 \mathrm{~m}^{2}$ é capaz de reduzir em $50 \%$ a demanda química de oxigênio (DQO) de $10 \mathrm{~m}^{3}$ de efluente/dia. O uso do CPC na mineralização de imidacloprid, methomyl, diuron e formetanato também evidenciou sua versatilidade na degradação de pesticidas ${ }^{53}$. Estes reatores, bem como outros aspectos relacionados à utilização da energia solar em processos de descontaminação, estão detalhadamente descritos no livro de Gálvez e Rodríguez ${ }^{50}$, também disponível em formato pdf na página da Unesco ${ }^{53}$.

Reatores mais simples também têm possibilitado a degradação eficiente de diversos contaminantes orgânicos. Nogueira e colaboradores $^{43}$ utilizaram frascos de vidro âmbar para simular reatores em batelada tipo tanque. No estudo foi avaliada a influência da agitação e da profundidade de solução (4,5 até $14 \mathrm{~cm})$ na degradação de ácido dicloroacético. Em todos os experimentos a agitação da solução apresentou pouca influência sobre o processo. Também foi observado que para menores profundidades a remoção de carbono orgânico total é maior devido a limitações por transferência de luz.

Nogueira e Modé ${ }^{35}$ compararam o efeito da irradiação solar e artificial na fotodegradação de fenol e diferentes clorofenóis (mono, di e triclorofenol), mediada por ferrioxalato. Ambos os sistemas apresentaram resultados semelhantes na mineralização dos contaminantes. No entanto, o sistema utilizando irradiação solar tem a vantagem de reduzir os custos do processo. Este sistema também foi utilizado no tratamento de água de lavagem de vasilhames de herbicidas, que proporcionou total mineralização de uma mistura contendo os herbicidas diuron e tebuthiuron na presença de ferrioxalato e $\mathrm{H}_{2} \mathrm{O}_{2}$ após 30 min de irradiação solar ${ }^{56}$.

A variação da intensidade da irradiação solar durante o dia e o ano deve ser considerada em processos que utilizam esta fonte de energia, pois tem forte influência no tempo de residência do contaminante no reator. Nogueira e colaboradores ${ }^{43}$ avaliaram o efeito da intensidade luminosa em diferentes períodos do dia (entre 07:00 e 17:00 h) e do ano (janeiro a dezembro) na cidade de Araraquara, Brasil $\left(22^{\circ} \mathrm{S} 48^{\circ} \mathrm{O}\right)$ sob condições de céu claro. Foi observada uma diferença de $40 \%$ na remoção de COT de solução de ácido dicloroacético/ferrioxalato entre os meses de junho e janeiro e entre 9:00 e 12:00 h em um dia de verão, como consequiência da maior intensidade luminosa no verão e às 12:00 h, respectivamente.

Reator solar em fluxo do tipo tanque raso foi construído e aplicado à degradação de herbicidas ${ }^{27}$. Este consiste de recipiente plástico com área exposta de aproximadamente $0,1 \mathrm{~m}^{2}$ e 4,5 L de capacidade e $5 \mathrm{~cm}$ de profundidade, coberto com delgada placa de vidro (Figura 3). As soluções da amostra a ser tratada e dos aditivos necessários como solução de ferro, de ácido (para ajuste de pH) e de $\mathrm{H}_{2} \mathrm{O}_{2}$, são continuamente bombeadas para a base do reator, onde são irradiadas pela luz solar a vazões entre 4,5 e $18 \mathrm{~L} \mathrm{~h}^{-1}$. Após o total preenchimento do reator, a amostra tratada é descartada em um reservatório. Este tipo de reator é bastante interessante pela sua simplicidade de construção e operação. Uma vez que lagoas rasas já são bastante utilizadas em tratamentos biológicos na indústria, este tipo de reator pode ser usado em combinação com o tratamento biológico, como tratamento prévio ou posterior. Considerando que a intensidade da radiação solar é bastante variável, ajustes no tempo de irradiação da amostra durante o dia, o ano, e de acordo com as condições de nebulosidade são necessários para garantir suficiente eficiência de degradação e viabilizar a aplicação do processo contínuo, o que pode ser conseguida com a adequação da vazão de alimentação do reator, considerando a Equação 35:

$\mathrm{Q}=\mathrm{V} / \theta$

onde Q é a vazão de alimentação do reator, $\mathrm{V}$ é o volume do reator e $\theta$ é o tempo de residência da amostra no reator, que corresponde ao tempo de irradiação.

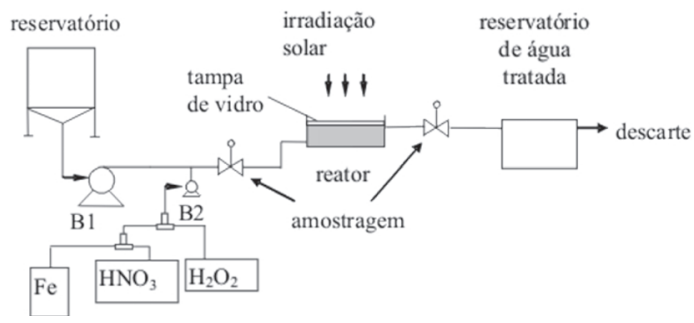

Figura 3. Representação esquemática do reator tipo lago raso para fotodegradação com energia solar 
Por outro lado, em sistemas em batelada com recirculação, o tempo de residência no reator não é tão importante uma vez que a solução é continuamente exposta à irradiação. Além disso, tanto em sistemas contínuos como batelada, a relação entre o volume irradiado e não irradiado é importante, uma vez que a reação de Fenton ocorre também na ausência de irradiação em todo o volume da reação.

\section{APLICAÇÕES DOS PROCESSOS FENTON E FOTO- FENTON AO TRATAMENTO DE EFLUENTES}

A composição diversificada dos efluentes pode limitar a eficiência de muitos processos convencionais de tratamento. Nas indústrias têxteis, por ex., é comum a presença de EDTA, tensoativos, enzimas, corantes, metais e outros compostos orgânicos, que po- dem afetar a proliferação de microorganismos e dificultar os tratamentos biológicos ${ }^{57}$. A coagulação, seguida de separação por flotação ou sedimentação são muito eficientes na remoção de material particulado de diversos efluentes. No entanto, para a remoção de cor e compostos orgânicos é necessária a aplicação de tratamentos complementares. É neste contexto que os processos Fenton e foto-Fenton surgem como uma alternativa viável ao tratamento de diversos tipos de efluentes. O Quadro 1 apresenta alguns exemplos dessas aplicações.

Os processos Fenton/foto-Fenton podem ser utilizados como único, pré e pós-tratamento de efluentes. Bandara e colaboradores ${ }^{77}$ estudaram a degradação de ácido $p$-nitrotolueno- $o$-sulfônico (pNTS), comumente encontrado em efluentes de indústrias químicas. Esses autores verificaram que a utilização do processo foto-Fenton promove a total mineralização do contaminante. No entanto, esses

Quadro 1. Efluentes passíveis de degradação por processo Fenton/foto-Fenton

\begin{tabular}{lc}
\hline Matriz & Alvo \\
\hline Efluente de & corantes JE Reverzol 3RS 150 e \\
indústria têxtil & RO Everzol 3BS 150 \\
& pigmentos azo: C.I.amarelo reativo 84 e \\
C.I. vermelho reativo 120 \\
álcool polivinílicol e corante R94H \\
corante Remazol Red $120(\mathrm{RR})$
\end{tabular}

\begin{tabular}{ll}
\hline Efluente de indústria & carga orgânica \\
papeleira & carga orgânica
\end{tabular}

DQO (324 -1874 mg L-1) Eficiência Ref.

Efluente de indústria carga orgânica

Eficiência
$40 \%$ de remoção de COT após
100 min de irradiação
$98 \%$ de descoloração
$96 \%$ de descoloração em 30 min
$98 \%$ de descoloração e $92 \%$ de
remoção de DQO
$88 \%$ de remoção de COT
$90 \%$ de remoção de COT
após 15 min de reação

min de reação

tabagista

\begin{tabular}{lc}
\hline Efluente de indústria & compostos fenólicos $(\mathrm{CF})$ \\
petroquímica (petrolífera) & gasolina e diesel
\end{tabular}

Efluente de indústria

DQO $\left(36,2 \mathrm{~g} \mathrm{O}_{2} \mathrm{~L}^{-1}\right)$

farmacêutica

\begin{tabular}{|c|c|c|c|}
\hline Chorume & carga orgânica & $60 \%$ de remoção de COT & 65,66 \\
\hline $\begin{array}{l}\text { Efluente de indústria } \\
\text { beneficiamento de azeite }\end{array}$ & $\begin{array}{c}\text { DQO } \\
\text { DQO, } \mathrm{DBO}_{5} \text { e compostos } \\
\text { fenólicos }(\mathrm{CF})\end{array}$ & $\begin{array}{l}\text { redução de } 76 \% \text { de DQO } \\
\text { redução de } 60 \% \text { de DQO, } \\
40 \% \text { de } \mathrm{DBO}_{5} \text { e } 100 \% \text { de CF }\end{array}$ & $\begin{array}{l}67 \\
68\end{array}$ \\
\hline $\begin{array}{l}\text { Efluente de indústria } \\
\text { de tintas }\end{array}$ & carga orgânica & $75 \%$ de remoção de COD & 69 \\
\hline $\begin{array}{l}\text { Efluente de indústria } \\
\text { de processamento de batatas }\end{array}$ & $\begin{array}{l}\text { formaldeído, melanina, uréia, extratos } \\
\text { de madeira, lignina entre outros }\end{array}$ & $\begin{array}{l}\text { redução de } 70 \% \text { de DQO } \\
\text { após } 800 \mathrm{~kJ} \mathrm{~m}^{-2}\end{array}$ & 54 \\
\hline $\begin{array}{l}\text { Efluente de indústria } \\
\text { de pesticidas }\end{array}$ & $\begin{array}{l}\text { formetanato, metamidofos, propamocarb, } \\
\text { imidacloprid, oxamyl, endossulfan } \alpha-\beta \text {, } \\
\text { lulenuron entre outros } \\
\text { DDT, DMDT, fenitrothion, } \\
\text { chlorfenvinphos entre outros }\end{array}$ & $\begin{array}{l}\text { 80\% de remoção de COT } \\
\text { após } 2 \text { h de irradiação } \\
\text { degradação média de } 90 \%\end{array}$ & 71 \\
\hline Efluente doméstico & $\begin{array}{l}\text { carga orgânica } \\
\text { DQO }\end{array}$ & $\begin{array}{l}\text { redução de } 82 \% \text { de } \mathrm{DQO} \text { e } 80 \% \text { de } \mathrm{DBO} \\
\text { redução de } 82 \% \text { de DQO }\end{array}$ & $\begin{array}{l}72 \\
73\end{array}$ \\
\hline $\begin{array}{l}\text { Efluente de indústria } \\
\text { de fermento }\end{array}$ & $\begin{array}{l}\text { carga orgânica devido à } \\
\text { Saccharomyces cerevisae }\end{array}$ & redução de $75 \%$ de DQO & 74 \\
\hline $\begin{array}{l}\text { Efluente de indústria } \\
\text { de processamento de cortiça }\end{array}$ & fenóis e compostos aromáticos & $98 \%$ de remoção de COT e $75 \%$ de fenóis & 75 \\
\hline Efluente de indústria bélica & $\begin{array}{c}\text { solução de explosivos de } 2,4,6 \text {-trinitrotolueno } \\
\text { (TNT) e hexaidro-1,3,5-trinitro- } \\
\text { 1,3,5-triazina (RDX) }\end{array}$ & 95\% de remoção de COT & 76 \\
\hline Efluente de indústria química & ácido $p$-nitrotolueno-o-sulfônico & redução de $95 \%$ de DQO & 77 \\
\hline
\end{tabular}

95\% de degradação de CF 63

remoção média entre 66 e $91 \%$ da 47 carga orgânica após 4,5 h redução de $90 \%$ de DQO após 10 min de experimento

64


autores enfatizam que neste caso não é economicamente viável a utilização do processo Fenton como tratamento único, pois em 30 min cerca de $60 \%$ da DQO é removida e o restante da carga orgânica é dificilmente degradada, encarecendo o processo. A DQO remanescente pode ser eficientemente mineralizada por processos biológicos $^{77}$. Kim e colaboradores ${ }^{65}$ e Lopez e colaboradores ${ }^{66}$ apresentaram resultados semelhantes na degradação de chorume, em que $60 \%$ do COT foi removido por processo foto-Fenton e o restante foi mineralizado biologicamente.

Também é muito comum o uso dos processos Fenton/foto-Fenton combinados a processos físico-químicos como acontece nas indústrias têxteis, onde inicialmente o material particulado e metais são removidos do efluente e posteriormente são aplicados os processos Fenton/foto-Fenton para remoção de cor, COT, odor ${ }^{59}$.

\section{REMEDIAÇÃO DE SOLOS CONTAMINADOS POR PROCESSO FENTON}

A remediação de solos tem recebido grande atenção, como resultado da crescente descoberta de locais contaminados ${ }^{78}$. Nos países da Comunidade Européia, já foram identificados aproximadamente 300.000 sítios contaminados ${ }^{79}$ e, de acordo com estimativas, este número poderá ser bem maior. Estima-se que somente na Inglaterra, Holanda e Alemanha o número de sítios contaminados possa chegar a $100.000,110.000$ e 200.000 , respectivamente ${ }^{80}$.

No Brasil existem poucos dados referentes à contaminação de solos, sendo que os existentes são na maioria das vezes relacionados ao Estado de São Paulo, onde a CETESB é a principal responsável pelos levantamentos. No período de 1992 a 2002 a CETESB atuou em cerca de 640 locais onde foram desenvolvidas atividades potencialmente poluidoras do solo e, de acordo com uma classificação com base em dados disponíveis até maio de 2002, 256 dessas áreas foram consideradas contaminadas ${ }^{79}$. Em maio de 2005, a CETESB $^{81}$ divulgou a existência de 1.504 sítios de contaminação, sendo $73 \%$ destes referentes a postos de combustíveis.

A remediação de solos é ainda uma atividade que está sob investigação, com inúmeros processos em vários estágios de desenvolvimento ${ }^{82}$. Dentre estes, os Processos Oxidativos Avançados têm surgido como uma alternativa para a remediação de solos contaminados $^{83}$. O poder oxidante das espécies ${ }^{\circ} \mathrm{OH}$ tem sido usado com sucesso na degradação de contaminantes orgânicos presentes no solo. Watts e colaboradores ${ }^{84}$ foram pioneiros no emprego do reagente de Fenton com esta finalidade. Em seus experimentos iniciais, pentaclorofenol presente em uma mistura de sílica-areia foi completamente mineralizado. Este estudo teve um papel importante na otimização do processo, pois estabeleceu que o $\mathrm{pH}$ ótimo para tratamento de solo é entre 2 e 3.

Posteriormente, Tyre e colaboradores ${ }^{85}$ observaram que minerais de ferro presentes no solo podem atuar como catalisadores na decomposição do peróxido de hidrogênio, dispensando a aplicação de ferro solúvel ao tratamento. Mostraram que a degradação de pentaclorofenol, hexadecano, trifluralina e dieldrin presentes em solo foi mais eficiente estequiometricamente (quantidade de $\mathrm{H}_{2} \mathrm{O}_{2}$ consumido por mol de contaminante) sem a adição de ferro solúvel.

Kong e colaboradores ${ }^{86}$ observaram que o ferro mineral (geotita e magnetita) presente no solo foi eficiente na degradação de uma mistura de diesel e querosene $\left(1,0 \mathrm{~g} \mathrm{~kg}^{-1}\right)$. Em experimentos isolados, quando foi utilizada magnetita $5 \%(\mathrm{~m} / \mathrm{m})$ como fonte de ferro, cerca de $80 \%$ dos contaminantes presentes no solo foram mineralizados, enquanto que a geotita $5 \%(\mathrm{~m} / \mathrm{m})$ mineralizou cerca de $60 \%$.

A atividade catalítica dos minerais de ferro hematita e magnetita também foi avaliada na degradação de pentaclorofenol em areia silicosa na presença de $\mathrm{H}_{2} \mathrm{O}_{2}{ }^{87}$. Os resultados mostraram que na presença de magnetita, o contaminante foi totalmente degradado em $12 \mathrm{~h}$, ao passo que na presença de hematita, apenas $12 \%$ do contaminante foram degradados, evidenciando a maior atividade da magnetita. A explicação dos autores para a melhor degradação quando se usa a magnetita em relação à hematita consiste no fato da magnetita ser constituída de $\mathrm{Fe}^{2+}$ e $\mathrm{Fe}^{3+}$ enquanto que a hematita é constituída basicamente de $\mathrm{Fe}^{3+}$, que catalisa a decomposição do peróxido de hidrogênio com menor velocidade que $\mathrm{Fe}^{2+}$. De maneira geral, minérios de ferro presentes no solo têm se mostrado muito eficientes na promoção da reação de Fenton. No entanto, em solo brasileiro, no qual a hematita é o mineral de ferro mais abundante, foi observado que o ferro mineral presente não foi um bom catalisador para a reação de Fenton na degradação de DDT, uma vez que somente $25 \%$ da concentração inicial de DDT foram degradados em 6 h sem adição de ferro solúvel, enquanto que $50 \%$ foram obtidos com a adição de ferro solúvel no mesmo tempo ${ }^{88}$. Estes resultados evidenciam que a composição mineral do solo pode ter grande influência na velocidade de degradação do contaminante. A granulometria do solo é outra propriedade importante que influencia significativamente a eficiência de degradação. A grande área superficial de solos ricos em argila favorece a adsorção dos contaminantes ao solo, diminuindo a disponibilidade dos mesmos para oxidação por radical hidroxila. Além disso, a baixa permeabilidade de solos argilosos dificulta a difusão dos reagentes de Fenton em tratamentos in situ. A concentração de matéria orgânica tem também grande importância na adsorção de contaminantes hidrofóbicos e no consumo de peróxido de hidrogênio ${ }^{89}$.

A concentração de $\mathrm{H}_{2} \mathrm{O}_{2}$ também está intimamente relacionada com a eficiência de degradação de contaminantes em solo. Em geral, os contaminantes, principalmente os hidrofóbicos, encontramse dissolvidos e/ou adsorvidos em componentes do solo, requerendo condições altamente oxidantes para serem degradados ${ }^{90}$. Sheldon e Kochi ${ }^{91}$ estabeleceram que substratos presentes em fases não aquosas dificilmente são atacados por radical hidroxila, devido a limitações causadas por transferência de massa. No entanto, concentrações elevadas de $\mathrm{H}_{2} \mathrm{O}_{2}\left(\geq 100 \mathrm{mmol} \mathrm{L}^{-1}\right)$ podem promover a transferência do radical hidroxila através da interface sólido-líquido e oxidar os contaminantes ${ }^{90}$. Outro fator favorável ao uso de concentrações elevadas de $\mathrm{H}_{2} \mathrm{O}_{2}$ é que a matéria orgânica comumente presente em solos pode competir no consumo de $\mathrm{H}_{2} \mathrm{O}_{2}$.

Villa e Nogueira ${ }^{89}$ observaram que baixas concentrações de $\mathrm{H}_{2} \mathrm{O}_{2}$ são suficientes para degradar aproximadamente $50 \%$ da concentração de DDT $\left(1,6 \mathrm{~g} \mathrm{~kg}^{-1}\right)$ presente em solo em um tempo de $2 \mathrm{~h}$. No entanto, degradações superiores somente são obtidas com elevadas concentrações de $\mathrm{H}_{2} \mathrm{O}_{2}\left(1,1 \mathrm{~mol} \mathrm{~L}^{-1}\right)$, quando adicionada sequencialmente durante $64 \mathrm{~h}$ atingindo $75 \%$ de degradação de DDT.

$\mathrm{O}$ emprego de solventes relativamente resistentes à oxidação, tais como cetonas, pode melhorar a eficiência de degradação de compostos hidrofóbicos, como alguns organoclorados ${ }^{92}$. Esses solventes são miscíveis em água e dissolvem os compostos alvo favorecendo, assim, a passagem dos mesmos para o meio aquoso, onde serão degradados.

Kong e colaboradores ${ }^{86}$ também observaram que a adição seqüencial de $\mathrm{H}_{2} \mathrm{O}_{2}$ é mais eficiente que a adição única no tratamento de solo contaminado com diesel. Quando foram feitos experimentos com a adição única de um mesmo volume de $\mathrm{H}_{2} \mathrm{O}_{2} 1$ e $15 \%$, a maior concentração apresentou maior eficiência de degradação. No entanto, quando foram feitas aplicações seqüenciais de $\mathrm{H}_{2} \mathrm{O}_{2} 1 \%$ obteve-se um resultado semelhante ao da aplicação única de $\mathrm{H}_{2} \mathrm{O}_{2}$ a $15 \%$.

Embora reações fotoquímicas desempenhem um importante papel na degradação de contaminantes orgânicos em meio aquoso, em solos estas ocorrem significativamente apenas em superfíci- 
$\mathrm{es}^{94}$. Segundo Scheunert e colaboradores ${ }^{94}$, em superfícies úmidas, tanto espécies adsorvidas a componentes do solo, quanto as em solução podem ser degradadas fotoquimicamente. Desta forma, é de se esperar que em tratamentos envolvendo a formação de lama os efeitos da irradiação sejam mais pronunciados. A diferença na eficiência de sistemas com lama irradiada e não irradiada, assim como os processos de tratamento em geral, vão depender de diversos fatores, entre eles as propriedades físico-químicas do contaminante e do solo contaminado, fatores biológicos e interações com outros contaminantes presentes no meio.

De maneira geral, os processos envolvendo formação de lama têm a vantagem de distribuir homogeneamente os reagentes no solo, facilitando a ação dos mesmos. Além do mais, dependendo das interações do contaminante com o solo e sua solubilidade em água, este pode passar para solução onde será mais facilmente degradado. Uma das grandes vantagens dos processos envolvendo reações de Fenton frente a processos convencionais é a possibilidade de aplicação in situ, que é restrita a poucos processos de tratamento. Oxidações in situ envolvendo $\mathrm{H}_{2} \mathrm{O}_{2}$ e $\mathrm{Fe}^{2+}$ (adicionado ou natural), podem atingir um alto grau de eficiência (>99\%) para compostos orgânicos como benzeno e tricloroetileno ${ }^{94}$. A aplicação in situ do oxidante ao solo pode ser feita usando-se poços, sondas, valas, entre outros. A escolha de um ou outro método de aplicação vai depender da superfície hidrológica e formação geoquímica do terreno ${ }^{94}$.

A Agência de Proteção Ambiental Americana (EPA) ${ }^{95}$ relata a implantação de instalações para o tratamento in situ de uma área com aproximadamente $8.100 \mathrm{~m}^{2}$ e mais de $20.000 \mathrm{~m}^{3}$ de solo contaminado com tricloroetileno, pentaclorofenol, xileno, benzeno e tolueno. Desses contaminantes, cerca de $31 \%$ era tricloroetileno, cuja concentração máxima (20,1 g por kg de solo) foi encontrada a 2,4 $\mathrm{m}$ de profundidade. No local foram instalados cerca de 255 injetores, a profundidades variando de 2,4 a $8 \mathrm{~m}$, por onde foram injetados $412.000 \mathrm{~L}$ de $\mathrm{H}_{2} \mathrm{O}_{2} 50 \%$. O custo de projetos como este está diretamente relacionado com características do solo, tipo e quantidade do contaminante, assim como a profundidade e maneira como estes estão distribuídos.

O exemplo anterior demonstra as vantagens da aplicação in situ de oxidantes ao solo. A maioria dos processos convencionais envolve remoção e/ou transporte do solo a ser tratado, o que é bastante dispendioso. No caso de um solo cujo contaminante encontra-se a $20 \mathrm{~m}$ de profundidade, a aplicação de oxidantes, tais como $\mathrm{H}_{2} \mathrm{O}_{2}$, ao solo é provavelmente a forma mais viável de tratamento.

A remediação de solos contaminados é um processo complexo e de alto custo. Custos ecológicos relacionados ao tratamento de solos são quase o dobro dos custos relacionados ao tratamento de ar e águas ${ }^{79}$. Neste contexto, o custo relativamente baixo do uso de reações de Fenton na remediação de solos é bastante incentivador.

\section{CONCLUSÕES}

Os processos Fenton e foto-Fenton aqui descritos apresentam grande eficiência na oxidação de uma ampla variedade de compostos orgânicos, tanto em meio aquoso como em solos. Vários fatores influenciam a velocidade de degradação, como a estrutura química do contaminante, $\mathrm{pH}$, concentração de ferro e de peróxido de hidrogênio e a carga orgânica presente. A simplicidade de aplicação dos processos e sua alta eficiência de degradação, principalmente quando sob irradiação, são seus principais atrativos. Suas limitações referem-se principalmente à estreita faixa de $\mathrm{pH}$ em que a eficiência de degradação é máxima (2,5-3,0), que tem sido contornada pela utilização de complexos de ferro que, além de estabilizar o ferro em uma faixa mais ampla de $\mathrm{pH}$, aumentam a eficiência de degradação principalmente sob irradiação solar. $\mathrm{O}$ aproveitamento da ener- gia solar é um dos pontos mais atraentes, pois reduz drasticamente os custos com energia.

Destacam-se alguns aspectos importantes que necessitam ser desenvolvidos como outros catalisadores de baixo custo, que possibilitem um bom aproveitamento da energia solar, que sejam estáveis em ampla faixa de $\mathrm{pH}$ e que possam ser facilmente recuperados, bem como a avaliação da toxicidade e da biodegradabilidade após tratamento de amostras complexas. Este último é um ponto fundamental para minimizar o custo do processo e principalmente garantir a qualidade do ambiente.

\section{AGRADECIMENTOS}

Os autores agradecem à FAPESPe ao CNPq pelo apoio financeiro.

\section{REFERÊNCIAS}

1. Wardmann, P.; J. Phys. Chem. Ref. Data 1989, 18, 1637.

2. Legrini, O.; Oliveros, E.; Braun, A. M.; Chem. Rev. 1993, 93, 671.

3. Andreozzi, R.; Caprio, V.; Insola, A.; Marotta, R.; Catal. Today 1999, 53, 51; Neyens, E.; Baeyens, J.; J. Hazard. Mater. 2003, 98, 33; Pera-Titus, M.; Garcia-Molina, V.; Banos, M. A.; Gimenez, J.; Esplugas, S.; Appl. Catal., B 2004, 47, 219.

4. Fenton, H. J. H.; J. Chem. Soc. 1894, 65, 899.

5. Haber, F.; Weiss, J.; Proc. Royal Soc. London 1934, 147, 332.

6. Rigg, T.; Taylor, W.; Weiss, J.; J. Chem. Phys. 1954, 22, 575; Walling, C.; Goosen, A.; J. Am. Chem. Soc. 1973, 95, 2987; Buxton, G. V.; Greenstock, C. L.; J. Phys. Chem. 1988, 17, 513.

7. Paterlini, W. C.; Nogueira, R. F. P.; Chemosphere 2005, 58, 1107.

8. Torrades, F.; Pérez, M.; Mansilla, H. D.; Peral, J.; Chemosphere 2003, 53, 1211.

9. Barbeni, M.; Minero, C.; Pelizzetti, E.; Borgarello, E.; Serpone, N.; Chemosphere 1987, 16, 2225

10. Bigda, R. J.; Chem. Eng. Prog. 1995, 12, 62.

11. O’ Neill, P.; Environmental Chemistry, $2^{\text {nd }}$. ed., Chapman \& Hall: Londres, 1995.

12. Sawyer, D. T.; Sobkowiak, A.; Matsushita, T.; Acc. Chem. Res. 1996, 29, 409; Bossmann, S. H.; Oliveros, E.; Göb, S.; Siegwart, S.; Dahlen, E. P.; Payawan, L.; Straub, M.; Worner, M.; Braun, A. M.; J. Phys. Chem. A 1998, $102,5542$.

13. Bates, H. G. C.; Uri, N.; J. Amer. Chem. Soc. 1953, 75, 2754.

14. Faust, B. C.; Hoigné, J.; Atmos. Environ. 1990, 24, 79.

15. Zuo, Y.; Hoigne, J.; Environ. Sci. Technol. 1992, 26, 1014.

16. Zepp, R. G.; Faust, B. C.; Hoigne, J.; Environ. Sci. Technol. 1992, $26,313$.

17. Langford, C. H.; Carey, J. H.; Can. J. Chem. 1975, 43, 2430.

18. Pignatello, J. J.; Environ. Sci. Technol. 1992, 26, 944.

19. Safarzadeh-Amiri, A.; Bolton, J. R.; Cater, S. R.; J. Adv. Oxid. Technol. 1996, 1,18 .

20. Pignatello, J. J.; Oliveros, E.; Mackay, A.; Environ. Sci. Technol. 2006, 36, 1.

21. Nogueira, R. F. P.; Guimarães, J. R.; Water Res. 2000, 34, 895.

22. Spinks, J.W.T.; Woods, R. J.; An Introduction to Radiation Chemistry, $3^{\text {rd }}$ ed. John Wiley \& Sons: Nova York, 1990.

23. Aplin, R.; Feitz, A. J.; Waite, T. D.; Water Sci. Technol. 2001, 44, 23.

24. Sun, Y. F.; Pignatello, J. J.; J. Agric. Food Chem. 1992, 40, 322.

25. Sabhi, S.; Kiwi, J.; Water Res. 2001, 35, 1994.

26. Lee,Y.; Jeong, J.; Lee, C.; Kim, S.; Yoon, J.; Chemosphere 2003, 51, 901.

27. Nogueira, R. F. P.; Silva, M. R. A.; Trovó, A. G.; Sol. Energy 2005, 74, 384.

28. Hatchard, C. G.; Parker, C. A.; Proc. Royal Soc. London 1956, 235, 518.

29. Safarzadeh-Amiri, A.; Bolton, J. R.; Carter, S. R.; Sol. Energy 1996, 56, 439.

30. Kwan, C. Y.; Chu, W.; Water. Res. 2003, 37, 4405.

31. Hislop, K. A.; Bolton, J. R.; Environ. Sci. Technol. 1999, 33, 3119.

32. Emilio, C. A.; Jardim, W. F.; Litter, M. I.; Mansilla, H. D.; J. Photochem. Photobiol., A 2002, 151, 121.

33. Chen, R.; Pignatello, J. J.; Environ. Sci. Technol. 1997, 31, 2399.

34. Nogueira, R. F. P.; Jardim, W. F.; J. Adv. Oxid. Technol. 1999, 4, 1; Bali, U.; Environ. Sci. Poll. Res. 2003, 10, 33.

35. Nogueira, R. F. P.; Modé, D.; Ecl. Quím. 2002, 27, 169.

36. Huston, P. L.; Pignatello, J. J.; Environ. Sci. Technol. 1996, 30, 3457.

37. Nansheng, D.; Feng, W.; Fan, L.; Zan, L.; Chemosphere 1997, 35, 2697; Sarria, V.; Deront, M.; Péringer, P.; Pulgarin, C.; Appl. Catal., B 2003, 40, 
231; Ghiselli, G.; Jardim W. F.; Litter, M. I.; Mansilla, H. D.; J. Photochem. Photobiol., A 2004, 167, 59

38. Bandara, J.; Morrison, C.; Kiwi, J.; Pulgarin, C.; Peringer, P.; J. Photochem. Photobiol., A 1996, 99, 57.

39. Park, H.; Choi, W.; J. Photochem. Photobiol., A 2003, 159, 241.

40. Sun, Y.; Pignatello, J. J.; Environ. Sci. Technol. 1993, 27, 304.

41. Parra, S.; Sarria, V.; Malato, S.; Péringer, P.; Pulgarin, C.; Appl. Catal., B 2000, 27, 153.

42. Rodriguez, M.; Timokhin, V.; Michl, F.; Contreras, S.; Jiménez, J.; Espulgas, S.; Catal. Today 2002, 76, 291

43. Nogueira, R. F. P.; Trovó, A. G.; Modé, D. F.; Chemosphere 2002, 48, 385.

44. Kositzi, M.; Poulios, I.; Malato, S.; Cáceres, J.; Campos, A.; Water Res. 2004, 38, 1147.

45. Minero, C.; Pelizzetti, E.; Malato, S.; Blanco, J.; Chemosphere 1993, 26, 2103.

46. Minero, C.; Pelizzetti, E.; Malato, S.; Blanco, J.; Sol. Energy 1996, 56, 421.

47. Moraes, J. E. F.; Silva, D. N.; Quina, F. H.; Chiavone-Filho, O.; Nascimento, C. A. O.; Environ. Sci. Technol. 2004, 38, 3746.

48. Teixeira, A. C. S. C.; Guardani, R.; Nascimento, C. A. O.; Ind. Eng. Chem. Res. 2003, 42, 5751

49. Will, I. B. S.; Moraes, J. E. F.; Teixeira, A. C. S. C.; Guardani, R.; Nascimento, C. A. O.; Sep. Purif. Technol. 2004, 34, 51.

50. Gálvez, J. B.; Rodríguez, S. M.; Solar Detoxification, Unesco: França, 2003.

51. Gernjak, W.; Krutzler, T.; Glaser, A.; Malato, S.; Caceres, J.; Bauer, R.; Fernández-Alba, A. R.; Chemosphere 2003, 50, 71.

52. Blanco, J.; Malato, S.; Maldonado, M. I.; Fallmann, H.; Krutzler, T.; Bauer, R.; J. Phys. IV 1999, 9, 259; Malato, S.; Blanco, J.; Cáceres, J.; FernándezAlba, A. R.; Aguera, A.; Rodríguez, A.; Catal. Today 2002, 76, 209; Malato, S.; Blanco, J.; Maldonado, M. I.; Fernández, P.; Alarcón, D.; Collares, M.; Farinha, J.; Oliveira, J.; Sol. Energy 2004, 77, 513; Amat, A. M.; Arques, A.; Miranda, M. A.; Seguí, S.; Sol. Energy 2004, 77, 559; Duarte, E. T. F. M.; Xavier, T. P.; Souza, D. R.; Miranda, J. A.; Machado, A. E. H.; Jung, C.; Oliveira, L.; Sattler, C.; Quim. Nova 2005, 28, 921.

53. Malato, S.; Blanco, J.; Vidal. A.; Alarcón, D.; Maldonado, M. I.; Cáceres, J.; Gernjak, W.; Sol. Energy 2003, 75, 329.

54. Machado, A. E. H.; Xavier, T. P.; Souza, D. R.; Miranda, J. A.; Duarte, E. T. F. M.; Ruggiero, R.; Oliveira, L.; Sattler, C.; Sol. Energy 2004, 77, 583.

55. http://unesdoc.unesco.org/images/0012/001287/128772e.pdf, acessada em Agosto 2005.

56. Trovó, A. G.; Villa, R. D.; Nogueira, R. F. P.; Quim. Nova 2005, $28,847$.

57. Neamtu, M.; Yediler, A.; Siminiceanu, I.; Kettrup, A.; J. Photochem. Photobiol., A 2003, 161, 87.

58. Rodriguez, M.;Sarria, V.; Esplugas, S.; Pulgarin, C.; J. Photochem. Photobiol., A 2002, 151, 129.

59. Kang, S. F.; Liao, C-H.; Po, S-T.; Chemosphere 2000, 41, 1287.

60. Meriç, S.; Selcuk, H.; Gallo, M.; Belgiorno, V.; Desalination 2005, 173, 239.

61. Perez, M.; Torrades, F.; Hortal, J. A. G.; Doménech, X.; Peral, J.; Appl. Catal., B 2002, 36, 63

62. Bozarslan, G.; Celebi, S. K.; Sengul F.; Water Sci. Technol. 1997, 36, 69.

63. Chen, J.; Rulkens, W. H.; Bruning, H.; Water. Sci. Technol. 1997, 35, 231.
64. Martínez, N. S. S.; Fernandez, J. F.; Segura, X. F.; Ferrer, A. S.; J. Hazard. Mater. 2003, 101, 315.

65. Kim, S. M.; Geissen, S. U.; Vogelpohl, A.; Water Sci. Technol. 1997, 35, 239.

66. Lopez, A.; Pagano, M.; Volpe, A.; Chemosphere 2004, 54, 1005.

67. Benitez, F. J.; Acero, J. L.; Gonzalez, T.; Garcia, J.; Process Biochem. 2001, $37,257$.

68. Vlyssides, A. G.; Loukakis, H. N.; Karlis, P. K.; Barampouti, E. M. P.; Mai, S. T.; Fresenius Environ. Bull. 2004, 13, 501.

69. Silva, M. R. A.; Oliveira, M. C.; Nogueira, R. F. P.; Ecl. Quim. 2004, $29,19$.

70. Fallmann, H.; Krutzler, T.; Bauer, R.; Z. Phys. Chem. 1999, 213, 67.

71. Barbunsiki, K.; Filipek, K.; Pol. J. Environ. Studies 2001, 10, 207.

72. Vlyssides, A. G.; Loukakis, H. N.; Karlis, P. K.; Environ. Technol. 2003, $24,931$.

73. Krzemieniewski, M.; Debowski, M.; Dobrzynska, A.; Zielinski, M.; Water Environ. Res. 2004, 76, 301.

74. Zak, S.; Environ. Technol. 2005, 26, 11 .

75. Peres, J. A.; Heredia, J. B.; Domínguez, J. R.; J. Hazard. Mater. 2004, 107, 115.

76. Oh, S. Y.; Cha, D. K.; Chiu, P. C.; Kim, B. J.; Water Sci. Technol. 2003 $47,93$.

77. Bandara, J.; Pulgarin, C.; Peringer, P.; Kiwi, J.; J. Photochem. Photobiol., A 1997, 111, 253.

78. Pierpoint, A. C.; Hapeman, C. J.; Torrents, A. Chemosphere 2003, 50, 1025

79. http://reports.is.eea.europa.eu/92-9157-202-0/en/page306.html, acessada em Agosto 2005.

80. Overcash, M.; Crit. Rev. Environ. Sci. Technol. 1996, 26, 337.

81. http://www.cetesb.sp.gov.br/Solo/areas_contaminadas/relacao_areas.asp, acessada em Agosto 2005.

82. Goubier, R.; Analusis 1994, 22, 25.

83. Chen, G.; Hoag, G. E.; Chedda, P.; J. Hazard. Mater. 2001, 87, 171

84. Watts, R. J.; Udell, M. D.; Rauch, P. A.; Waste Hazard. Mater. 1990, 7, 335.

85. Tyre, B. W.; Watts, R. J.; Miller, G. C.; J. Environ. Qual. 1991, 20, 832

86. Kong, S. H.; Watts, R. J.; Choi, J. H.; Chemosphere 1998, 37, 1473.

87. Watts, R. J.; Udell, M. D.; Kong, S. H.; Leung, S. W.; Environ. Eng. Sci. 1999, 16, 93; Watts, R. J.; Bottemberg, B. C.; Hess, T. F.; Jensen M. D.; Teel, A. L.; Environ. Sci. Technol. 1999, 33, 3432.

88. Villa, R. D.; Nogueira, R. F. P.; Ecl. Quim. 2005, 30, 69.

89. Villa, R. D.; Nogueira, R. F. P.; Sci. Total Environ. 2006, 371. 11

90. Watts, R. J.; Kong, S.; Dippre, M.; Barnes, W. T.; J. Hazard. Mater. 1994, $39,33$.

91. Metal-catalyzed Oxidations of Organic Compounds; Academic Press: New York, 1981 .

92. Zaleska, A.; Hupka, J.; Wiergowski. M.; J. Photochem. Photobiol., A 2000, 135, 213.

93. Scheunert, I.; Masour, M.; Dorfler, U.; Schroll, R.; Sci. Total Environ. 1993 132,361 .

94. Gates, D. D.; Siegrist, R. L.; J. Environ. Eng-Asce 1995, 121, 639.

95. http://www.clu-in.org/download/remed/chemox.pdf, acessada em Setembro 2005 